\title{
The Influence of Microgravity on Invasive Growth in Saccharomyces cerevisiae
}

\author{
Sebastiaan E. Van Mulders, ${ }^{1, *}$ Catherine Stassen, ${ }^{2, \star}$ Luk Daenen, Bart Devreese, ${ }^{2}$ Verena Siewers, ${ }^{3}$ \\ Rudy G.E. van Eijsden, ${ }^{4}$ Jens Nielsen, ${ }^{3}$ Freddy R. Delvaux, and Ronnie Willaert ${ }^{5}$
}

\begin{abstract}
This study investigates the effects of microgravity on colony growth and the morphological transition from single cells to short invasive filaments in the model eukaryotic organism Saccharomyces cerevisiae. Two-dimensional spreading of the yeast colonies grown on semi-solid agar medium was reduced under microgravity in the $\Sigma 1278$ b laboratory strain but not in the CMBSESA1 industrial strain. This was supported by the $\Sigma 1278 \mathrm{~b}$ proteome map under microgravity conditions, which revealed upregulation of proteins linked to anaerobic conditions. The $\Sigma 1278 \mathrm{~b}$ strain showed a reduced invasive growth in the center of the yeast colony. Bud scar distribution was slightly affected, with a switch toward more random budding. Together, microgravity conditions disturb spatially programmed budding patterns and generate strain-dependent growth differences in yeast colonies on semi-solid medium. Key Words: Microgravity-Saccharomyces cerevisiae-Adhesion-Invasive growth-Budding-Proteomics. Astrobiology 11, 45-55.
\end{abstract}

\section{Introduction}

S PaCeflight conditions affect single-cell and complex multicellular organism physiology (Nickerson et al., 2000; West, 2000). These alterations may have important consequences for human spaceflights. Microbes were reported to grow faster or to become more virulent in microgravity conditions, which has been shown in murine infection models (Nickerson et al., 2000; Wilson et al., 2007; Rosenzweig et al., 2010). Furthermore, parts of the human immune system are suppressed under these conditions (Taylor et al., 1997; Sonnenfeld, 1999; Borchers et al., 2002; Sonnenfeld, 2002). Together, the knowledge of microbial behavior in microgravity is indispensable to assure human resistance to illness during spaceflights.

Most microbial microgravity studies have focused on a single-cell level, both on semi-solid media and in liquid cultures under ideal laboratory conditions. In nature, yeasts frequently switch over between a unicellular and a more complex differentiated multicellullar lifestyle (Palková and Vachová, 2006; Granek and Magwene, 2010). The budding yeast Saccharomyces cerevisiae, for example, may adopt various multicellular structures such as complex colonies, flocs, filaments, mats, and biofilms (Verstrepen and Klis, 2006). In a process called flocculation, yeast flocs are formed, which consist of thousands of cells in a very dense organization and offer cells inside the floc protection from multiple stresses such as ethanol and antimicrobials (Smukalla et al., 2008). On agar surfaces, starvation for carbon sources causes a developmental switch in haploid cells that elongates the cell shape and changes polarization and budding from an axial to a unipolar orientation (Cullen and Sprague, 2000). Cells remain physically attached to each other, are delayed in G2/M period [i.e., the post-synthetic gap (G2) and mitosis (M) phases during the yeast cell cycle], and stick strongly to the agar (Kron et al., 1994), which allows them to form filaments that help to forage for nutrients by the invasion of agar medium. This process is called invasive growth (Roberts and Fink, 1994; Cullen and Sprague, 2000; Braus et al., 2003).

Adherence and invasion of a foreign substrate are the first indispensable steps for yeasts to colonizing host sites (Blankenship and Mitchell, 2006). In otherwise harmless S. cerevisiae cells, these mechanisms are gaining interest, considering the increasing numbers of reports of infections in immunocompromised patients (Goldstein and McCusker, 2001; Graf and Gavazzi, 2007). Two virulence traits similar to

\footnotetext{
${ }^{1}$ Centre for Malting and Brewing, Katholieke Universiteit Leuven, Heverlee, Belgium.

${ }^{2}$ Laboratory for Protein Biochemistry and Biomolecular Engineering, Ghent University, Ghent, Belgium.

${ }^{3}$ Systems Biology, Chalmers University of Technology, Göteborg, Sweden.

${ }^{4}$ VIB Microarray Facility, Leuven, Belgium.

${ }^{5}$ Laboratory of Structural Biology, Vrije Universiteit Brussel, Brussels, Belgium.

*Both authors contributed equally to this work.
} 
those identified in other pathogenic fungi were reported: the ability to grow at elevated temperatures and filament formation (McCusker et al., 1994a, 1994b). Candida albicans, a related fungus, is more frequently reported to be responsible for a range of infections, from those that are harmless, simple mucosal in nature to systemic infections with a high mortality rate (Gullo, 2009; Evans, 2010). The strong adhesion of C. albicans to surfaces such as on pacemakers and prosthetic heart valves or joints explains the high number of medical implant-related fungal infections (Kojic and Darouiche, 2004; Ramage et al., 2006). The yeast-to-filament transition further enhances tissue invasion of Candida cells and promotes survival and immune evasion (Hube, 2004; Kumamoto and Vinces, 2005). Both fungi rely on very similar cell surface proteins to initiate adherence, which are generally called adhesins (Dranginis et al., 2007; Klis et al., 2009). For S. cerevisiae, these lectin-like proteins are encoded by the FLO ("flocculation") genes (Teunissen and Steensma, 1995; Van Mulders et al., 2009). One of these adhesins is Flo11p, which is required for filament formation and surface adhesion (Lambrechts et al., 1996; Lo and Dranginis, 1996; Reynolds and Fink, 2001). Another important adhesin is Flo1p, which strongly binds to mannan targets in the yeast cell wall and collects numerous cells into a macroscopic floc (Bony et al., 1997; Kobayashi et al., 1998). Depending on the yeast strain, these adhesins may fulfill different roles in these morphogenic events (Guo et al., 2000). Yeast strains were observed in which Flo11p was involved in flocculation or Flo1p in a strong adhesion to surfaces (Reynolds and Fink, 2001; Bayly et al., 2005; Douglas et al., 2007; Fichtner et al., 2007; Van Mulders et al., 2009).

In microgravity, the budding pattern of haploid and diploid $S$. cerevisiae cells grown in liquid culture medium was found to be disturbed, indicated by an increased proportion of randomly distributed bud scars (Walther et al., 1996; Johanson et al., 2007). A disturbed budding pattern, and gene expression changes related to budding, were also observed during experiments with simulated or low-shear modeled microgravity (LSMMG) (Purevdorj-Gage et al., 2006; Sheehan et al., 2007). Moreover, an increased tendency of cells to form aggregates containing five or more cells, together with a downregulation of cell separation genes (DSE1, DSE2, and EGT2), was noticed in simulated microgravity (PurevdorjGage et al., 2006). Changes in gene expression were found under microgravity conditions regarding the stress response element genes SSA4, YIL052C, and YST2 with transcription regulation involving Sfp1p and Msn4p (Coleman et al., 2008). Spaceflight also induces significant changes in cell wall thickness for different S. cerevisiae strains (Liu et al., 2008). Nevertheless, little is known about how microgravity affects adhesin-dependent multicellular organization and how this contributes to possible health implications for human spaceflight, for example, by the increased pathogenicity of microscopic organisms. Indeed, C. albicans cells were shown to be more intensely organized in filaments in simulated microgravity, which is consistent with enhanced pathogenicity (Altenburg et al., 2008).

In the framework of microbial safety during spaceflights, insights into the microbial multicellular organization level in microgravity should complement the current knowledge at a single-cell level. The tractable and harmless microorganism, S. cerevisiae, offers important advantages for microbial mul- ticellular structure research in microgravity, such as its GRAS (Generally Recognized as Safe) classification and powerful genetic tools. In this study, a laboratory and an industrial S. cerevisiae strain, $\Sigma 1278 b$ and CMBSESA1, were grown on a semi-solid culture medium during 12 days at the International Space Station (ISS). The haploid laboratory $\Sigma 1278$ b strain grows invasively and is defective in the induction of stress-responsive genes (Stanhill et al., 1999). The industrial CMBSESA1 strain, however, originates from a brewery environment in which cells are adapted to stress conditions, such as high osmotic and ethanol concentrations, and does not grow invasively. During this mission, the twodimensional spreading of the colonies was monitored by image analysis. Postflight analysis included the assessment of invasive growth, bud scar distribution, and proteome changes compared to normal gravity ground controls.

\section{Materials and Methods}

\subsection{Yeast strains and prelaunch culture conditions}

Saccharomyces cerevisiae $\Sigma 1278$ b MAT $\alpha$ leu2 was kindly obtained from the Laboratory of Molecular Cell Biology (Katholieke Universiteit Leuven). An industrial yeast strain (CMBSESA1) with an unknown genotype was kindly obtained from a Belgian brewery. Prelaunch preparation of the experiment, assembly, and safety control were performed within $24 \mathrm{~h}$ prior to launch in a laboratory at the launch site (Baikonur, Kazakhstan). Yeast cells were suspended in isotonic saline $\left[0.9 \%\left(\mathrm{w} \mathrm{v}^{-1}\right) \mathrm{NaCl}\right]$ at a concentration of $1 \times 10^{6}$ cells $\mathrm{mL}^{-1}$. Cells were inoculated in 4-fold onto the surface of $2.5 \mathrm{~mL}$ YPD agar $\left[1 \%\left(\mathrm{w} \mathrm{v}^{-1}\right)\right.$ yeast extract, $2 \%\left(\mathrm{w} \mathrm{v}^{-1}\right)$ peptone, $2 \%\left(\mathrm{w} \mathrm{v}^{-1}\right)$ glucose, and $0.8 \%$ or $2 \%\left(\mathrm{w} \mathrm{v}^{-1}\right)$ agar] in 12-well culture plates (CellStar, Greiner Bio-One, Belgium) with a sterile wooden rod. Two culture plates were sealed hermetically in one polycarbonate Biocontainer (PedeoTechniek, Oudenaarde, Belgium) and vacuum sealed in a highly transparent Minigrip polyethylene bag (60 $\mu \mathrm{m}$ thick). From that point on, the same procedures as for the BASE-A experiment were followed as described previously (Leys et al., 2009). Temperature and radiation were logged as described previously (Goossens et al., 2006; Vanhavere et al., 2008).

A control experiment, parallel to the flight experiment, was set up at the launch site and remained at approximately $22^{\circ} \mathrm{C}$, because no real-time temperature data from the ISS was available. Therefore, a postflight ground experiment was set up in a programmable incubator with use of the logged temperature data (Fig. 1). The samples from this second ground experiment were used to compare directly with the spaceflight samples.

\subsection{Microgravity conditions}

During the two-day trip in the Soyuz TMA-9 vehicle to the ISS, the pouches were kept at $22 \pm 1^{\circ} \mathrm{C}$. The experimental packages were returned unopened from the ISS with the Soyuz TMA- 8 vehicle after a total of 12 flight days. The experimental packages were transported at about $4{ }^{\circ} \mathrm{C}$ in an active controlled thermal container without exposure to airport X-ray scanning from the landing area to the Katholieke Universiteit Leuven (Leuven, Belgium) within $40 \mathrm{~h}$ after landing. The analysis of the samples was started immediately. 


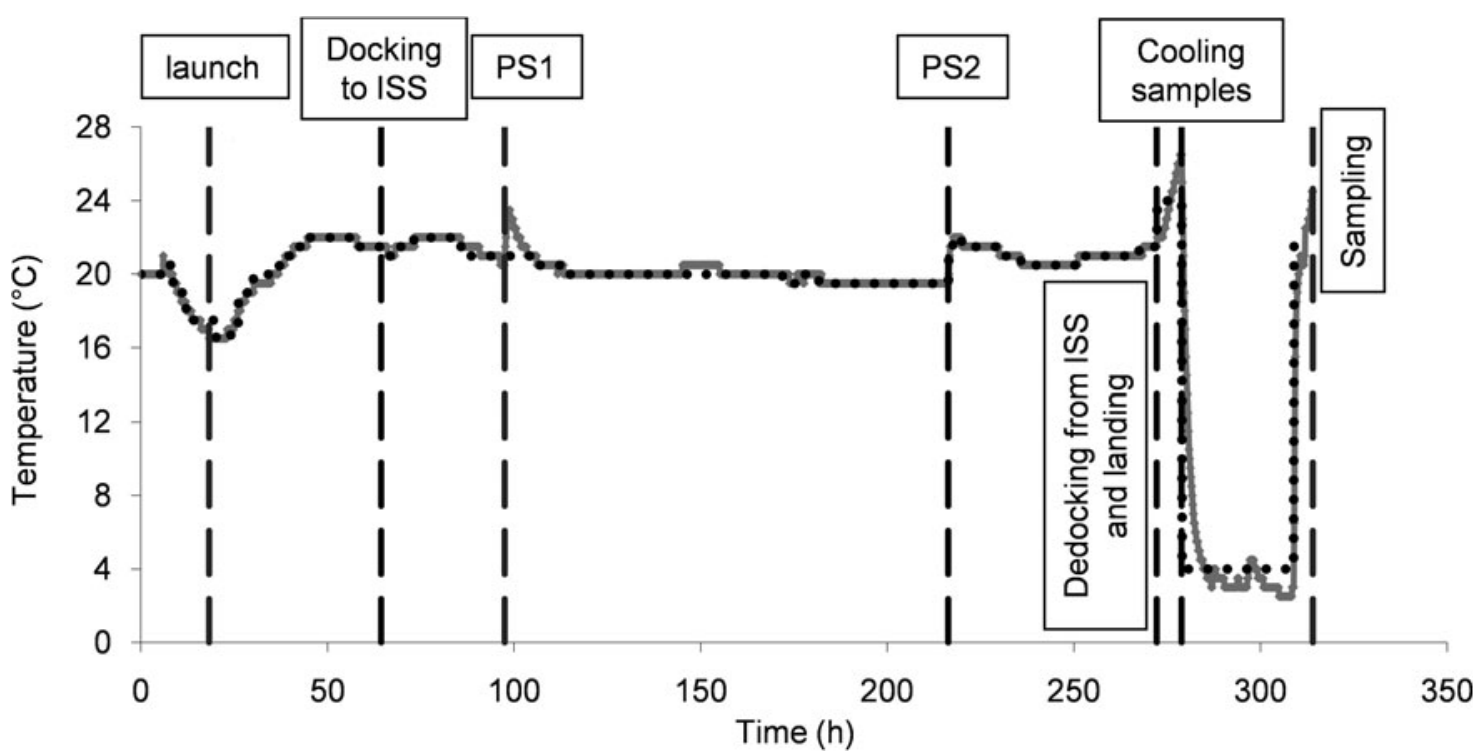

FIG. 1. Time-temperature schedule of the microgravity experiment (full gray line) and the postflight ground experiment (black dotted line), in which the microgravity sample temperature at the ISS was simulated. At $0 \mathrm{~h}$, the inoculation of the yeast samples on the agar plates took place. The first indicated time point at $18.3 \mathrm{~h}$ shows the launch time. The second time point is the docking from Soyuz TMA-9 to the ISS. The first and second photo sessions (PS1 and PS2) are indicated at 97.5 h and $216.3 \mathrm{~h}$. Dedocking and landing were initiated at $272 \mathrm{~h}$. Samples were cooled at $278 \mathrm{~h}$, and sampling took place approximately at $314 \mathrm{~h}$.

\subsection{In-flight analyses}

Colony morphology was assessed by photographing the plates at two time points in orbit, after $97.5 \mathrm{~h}$ and $216.3 \mathrm{~h}$ (Fig. 1). For the ground reference experiments, photographs were taken every day. With ImageJ image analysis software (Abramoff et al., 2004), an estimation of the two-dimensional spreading was performed by measuring the surface area of the yeast colonies. To standardize each measurement, we used the well surface area as a reference. A linear radial growth model was used to fit the experimental data during the linear growth phase and to determine the radial growth rate constant $C_{r}$ : $S=C_{r} t+S_{0}$ (where $S$ is the relative colony surface area at time $t$, and $S_{0}$ the surface area at an initial radius) (Pirt, 1967).

\subsection{Invasive growth}

Cells were collected from the agar surfaces with a sterile cell scraper, without damaging the agar surface. The amount of invasively growing cells in the agar are a measure for invasive growth (Roberts and Fink, 1994; Braus et al., 2003; Van Mulders et al., 2009); the cells were documented by photographing the agar with a Nikon SMZ800 stereomicroscope equipped with a DN100 camera.

\subsection{Analysis of budding pattern}

Cell samples were subdivided and used for microscopic analysis. Staining of bud scars was carried out according to the method described by Lord et al. (2002). Briefly, cells were fixed by formaldehyde (3.7\%) and washed twice with water. Chitin, which is concentrated in the bud scars, was visualized after treating the cells with Calcofluor White $\left(1 \mathrm{mg} \mathrm{mL}^{-1}\right)$ (Sigma, Belgium) (Pringle, 1991). The cells were subsequently resuspended in $20 \mathrm{mM} \mathrm{CaCl} 2$ and $20 \mathrm{mM} \mathrm{MnSO}_{4}$ buffer solution. To immobilize the cells, the microscope slides were immersed in Concanavalin A (Sigma, Belgium)-PBS solution $\left(0.1 \mathrm{mg} \mathrm{mL}^{-1}\right.$ Con A) at room temperature for $15 \mathrm{~min}$. Next, the slide was washed briefly with $95 \%$ ethanol and dried. A $5 \mu \mathrm{L}$ volume of sample was mounted onto the slide, and the stained cells were observed by epifluorescence microscopy with a $100 \times$ oil objective lens and DAPI filter cube or by confocal microscopy on a Nikon T2000-Eclipse C1 microscope equipped with a Violet Diode UV laser $(408 \mathrm{~nm})$. A UV filter cube with a $420 \mathrm{~nm}$ long-pass barrier filter was used in the PMT detector box of the confocal system. For each sample, at least 150 cells with three or more bud scars were analyzed. The percentage of axial, unipolar, and random budding was determined for each sample. The data presenting the budding patterns were calculated from three replicate samples.

\subsection{Proteomics}

2.6.1. Protein extraction. Yeast cells were harvested as described above and proteins extracted as follows: Yeast cells were washed with GTE buffer [50 mM Tris pH 7.4, 10\% glycerol, $1 \mathrm{mM}$ EDTA] and centrifuged (13,000 rpm, $20 \mathrm{~min})$. After resuspension of the pellet in $500 \mu \mathrm{L}$ lysis buffer [7M urea, $2 M$ thiourea, $2 \%\left(\mathrm{w} \mathrm{v}^{-1}\right)$ CHAPS, $1 \%\left(\mathrm{w} \mathrm{v}^{-1}\right)$ DTT, $0.8 \% \quad\left(\mathrm{v} \mathrm{V}^{-1}\right)$ amopholites, protease inhibitor cocktail (Roche)], acid-washed glass beads [450-600 $\mu \mathrm{m}$ (Sigma)] were added, and cells were lysed by vortexing 5 times for $30 \mathrm{~s}$ and centrifuged $(10,000 \mathrm{~g}$ for $20 \mathrm{~min})$. The supernatant containing the soluble proteins was desalted and concentrated by using $5 \mathrm{~K}$ Vivaspin (Sartorius). Subsequently, the protein concentration was determined with the Bradford assay (Pierce Biotechnology, Thermo Scientific).

2.6.2. Differential proteomics using two-dimensional polyacrylamide gel electrophoresis (2D-PAGE). During $10 \mathrm{~h}, 150 \mu \mathrm{g}$ of protein was actively rehydrated $(50 \mathrm{~V})$ on 
$17 \mathrm{~cm}$ ReadyStrip IPG strips (immobilized $\mathrm{pH}$ gradient 3-10) (Biorad). Subsequently, isoelectric focusing was performed on the Protean IEF cell (Biorad). Parameters were set to $150 \mathrm{~V}$ (10 min), $150 \mathrm{~V}(2 \mathrm{~h}), 300 \mathrm{~V}(10 \mathrm{~min}), 300 \mathrm{~V}(1 \mathrm{~h}), 1 \mathrm{kV}(2 \mathrm{~h})$, $10 \mathrm{kV}(1 \mathrm{~h}), 10 \mathrm{kV}(30 \mathrm{kVh}), 500 \mathrm{~V}(10 \mathrm{~min})$, and $500 \mathrm{~V}$.

Prior to sodium dodecyl sulfate polyacrylamide gel electrophoresis (SDS-PAGE), the IPG strips were equilibrated for 10 min with reducing buffer [6M urea, $2 \%\left(\mathrm{w} \mathrm{v}^{-1}\right)$ sodium dodecyl sulfate (SDS), $1 \%\left(\mathrm{w} \mathrm{v}^{-1}\right)$ dithiotreitol], $10 \mathrm{~min}$ with alkylation buffer [ $6 \mathrm{M}$ urea, $2 \%\left(\mathrm{w} \mathrm{v}^{-1}\right)$ SDS, $5 \%\left(\mathrm{w} \mathrm{v}^{-1}\right)$ iodoacetamide], and finally $5 \mathrm{~min}$ in the electrophoresis buffer [192 mM Glycine, $25 \mathrm{mM}$ Tris, $0.1 \%\left(\mathrm{w} \mathrm{v}^{-1}\right)$ SDS]. The equilibrated IPG strips were placed on top of $12 \%$ polyacryl amide gels and covered with $0.5 \%$ melted agarose containing a trace of bromophenolblue. A voltage of $200 \mathrm{~V}$ was applied to the gels until the bromophenolblue front migrated off the gels. Proteins were visualized with the fluorescent stain Krypton (Pierce Biotechnology, Thermo Scientific). Afterward, the gels were stained with colloidal Coomassie G250. The fluorescent-stained gel images were analyzed with Proteomweaver software (Biorad). Parameters for detection of differential proteins were set to a regulation factor of 2 , a coefficient of variation lower than $60 \%$, and a presence of the spot in 2 out of 3 gel replicas.
2.6.3. Protein identification. After detection of differential proteins, the spots were excised manually from the 2Dgel, and in-gel tryptic digestion was performed. First, the gel spots were washed twice with $50 \%$ acetonitrile (ACN)/ $200 \mathrm{mM} \mathrm{NH} \mathrm{HCO}_{3}$ for $20 \mathrm{~min}$ at $30^{\circ} \mathrm{C}$. Subsequently, the spots were dried, a $1 / 50$ dilution of $0.1 \mu \mathrm{g} \mu \mathrm{L}^{-1}$ trypsin (Promega) was added, and after $45 \mathrm{~min}$ on ice $50 \mathrm{mM}$ $\mathrm{NH}_{4} \mathrm{HCO}_{3}$ was added until the spots were completely submerged. Digestion was performed by overnight incubation at $37^{\circ} \mathrm{C}$. Extraction of the peptides from the gel pieces was achieved by adding twice $60 \% \mathrm{ACN} / 0.1 \% \mathrm{HCOOH}$ to the gel spots. The final volume of extraction buffer was dried in a Speedvac, and finally the peptides were dissolved in $8 \mu \mathrm{L}$ $0.1 \% \mathrm{HCOOH}$. Five-tenths microliter of peptide mixture was spotted on a stainless steel MALDI target plate and covered with $0.5 \mu \mathrm{L}$ alpha-cyano-4-hydroxy cinnamic acid matrix (7 mg mL $\mathrm{mL}^{-1}$ in $50 \%$ ACN, $0.1 \%$ TFA, $1 \mathrm{mM}$ ammonium citrate). Identification of the proteins was obtained by measuring the peptide mass fingerprint on a MALDI-TOF/TOF MS system (4700 Proteomics Analyzer, Applied Biosystems) in MS mode. On selected peptides, tandem mass spectrometry (MS/MS) was performed for verification of the sequence. The obtained spectra were searched against a $S$. cerevisiae database, downloaded from NCBI, with an "in-
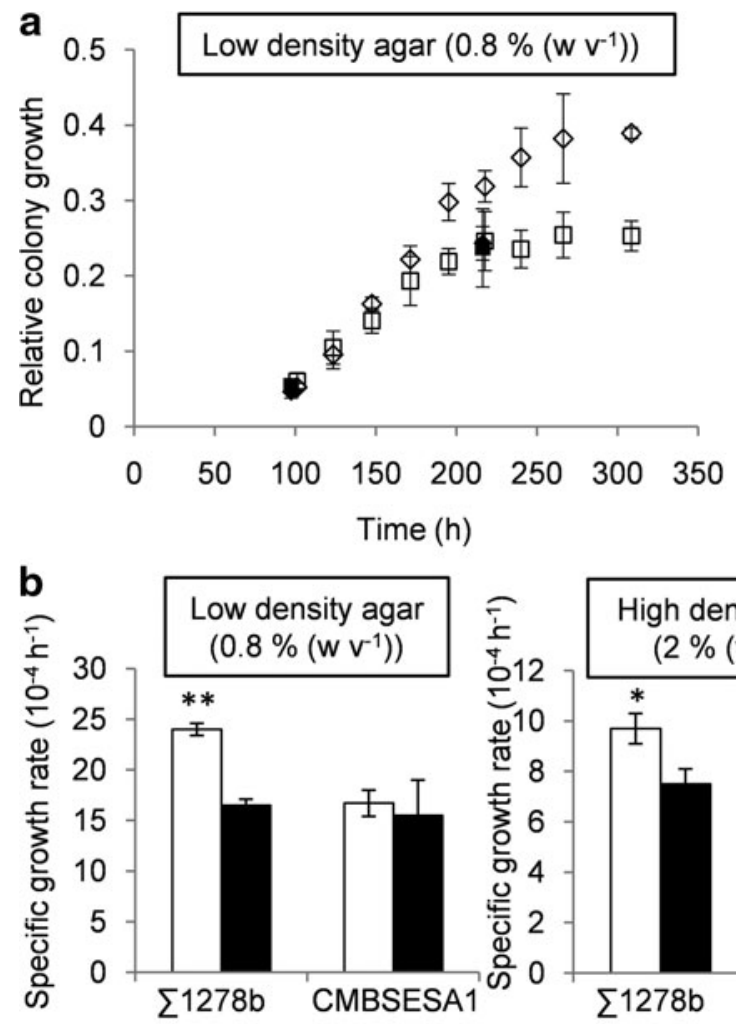

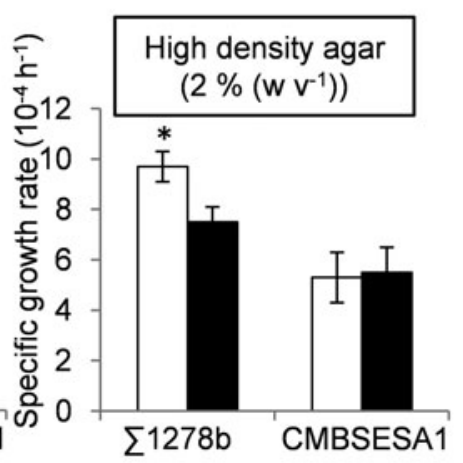

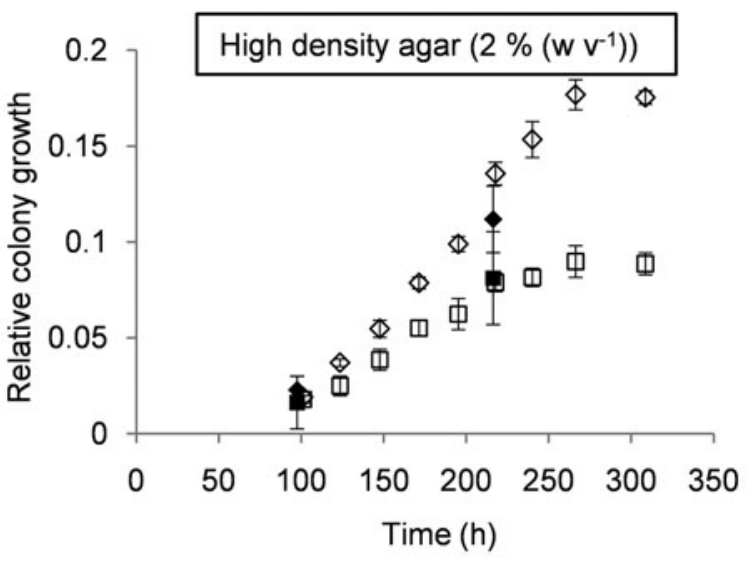

C

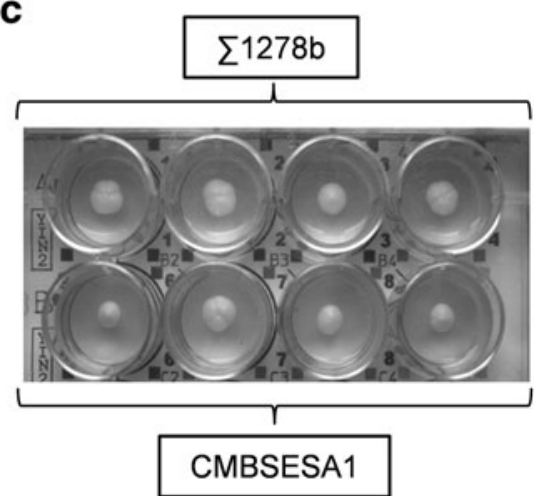

FIG. 2. (a) Colony growth curves of $\Sigma 1278 \mathrm{~b}(\diamond)$ and CMBSESA1 $(\square)$ on $0.8 \%$ and $2 \%$ YPD agar in normal gravity. At two time points, $97.5 \mathrm{~h}$ and $216.3 \mathrm{~h}$ after inoculation of the yeast, the yeast colony growth at the ISS was estimated by taking photographs for the $\Sigma 1278$ b strain $(\bullet)$ and industrial strain $(\boldsymbol{\square})$. (b) Specific growth rate $\left(\times 10^{-4} \mathrm{~h}^{-1}\right)$ on $0.8 \%$ YPD agar $($ left $)$ and $2.0 \%$ YPD agar (right) of the colonies (white bars, normal gravity; black bars, microgravity). (c) Photograph taken at the ISS after $216.3 \mathrm{~h}$ of growth, $\Sigma 1278 \mathrm{~b}$ strain (top row, four replicates) and industrial strain (bottom row, four replicates). Asterisks indicate statistically significant differences between ground and space samples $\left({ }^{*} p<0.05\right.$; $\left.{ }^{* *} p<0.01\right)$; error bars correspond to the standard deviation. 
house" Mascot platform. The spectra were searched by using 100 ppm peptide mass and 0.5 Da MS/MS tolerance with carbamidomethylation (Cys) and oxidation (Met) as variable modification parameters. Proteins were positively identified when at least 2 MS/MS fragmentation spectra were significantly identified according the Mascot algorithm (Matrixscience, London, UK) or when the peptide sequence was manually interpreted.

\section{Results}

\subsection{Yeast colony growth}

Yeast cells were grown on YPD agar plates during $300 \mathrm{~h}$ at an average temperature of $19.2^{\circ} \mathrm{C}$ (Fig. 1). Colony morphology was assessed by photographing the plates at two time points in orbit, after $97.5 \mathrm{~h}$ and $216.3 \mathrm{~h}$ (Fig. 2C). For the ground reference experiments, photographs were taken every day. Both the CMBSESA1 and $\Sigma 1278$ b yeast colonies covered a larger surface on $0.8 \%$ agar than $2 \%$ agar throughout the experiment (Fig. 2A), which is in accordance with previous studies in which low-density agar surfaces generate the most intensive colony spreading (Reynolds and Fink, 2001). The two-dimensional spreading of the CMBSESA1 colonies at two time points, $97.5 \mathrm{~h}$ and $216.3 \mathrm{~h}$, and the relative colony growth rate in microgravity were comparable with the measurements in normal gravity on $2 \%$ and $0.8 \%$ agar (Fig. 2A, 2B). In contrast, the $\Sigma 1278$ b yeast strain had a significantly larger colony surface under normal gravity conditions than under microgravity conditions at both agar concentrations at $216.3 \mathrm{~h}$ (Fig. 2A). The differences in spreading were more pronounced on the lower density $0.8 \%$ agar. Moreover, the relative colony growth rate of the $\Sigma 1278$ b strain was significantly decreased under microgravity conditions at both agar concentrations (Fig. 2A). Total cell count in this experiment was not assessed because a significant portion of the cells were growing invasively into the agar.

\subsection{Invasive growth}

Postflight handling of the samples included the collection of yeast cells by scraping them off the agar plates. Afterward, the remaining cells in the agar were photographed to assess invasive growth (Fig. 3). $\Sigma 1278$ b strain showed more invasive growth on $2 \%$ agar than on $0.8 \%$ agar (data not shown). This is a Flo11p-associated phenotype, since no invasive growth was observed in a preliminary experiment when using a $\Sigma 1278$ b flo11 1 strain (results not shown). Interestingly, under microgravity, the $\Sigma 1278$ b samples showed reduced invasive growth in the middle of the colony on $2 \%$ agar. The industrial strain CMBSESA1 showed no invasive growth for any condition tested.

\subsection{Yeast budding pattern}

The influence of microgravity on the bud scar pattern of the $\Sigma 1278$ b strain and the industrial brewer's CMBSESA1 strain was examined. The bud scar patterns were classified into random, unipolar, and axial. Figure 4 shows the general distribution of bud scar patterns of (A) $\Sigma 1278 b$ cells and (B) CMBSESA1 cells, grown on $2 \%$ YPD agar in normal gravity and microgravity. For $\Sigma 1278$ b, the majority of cells showed an axial budding pattern, which is expected for this haploid
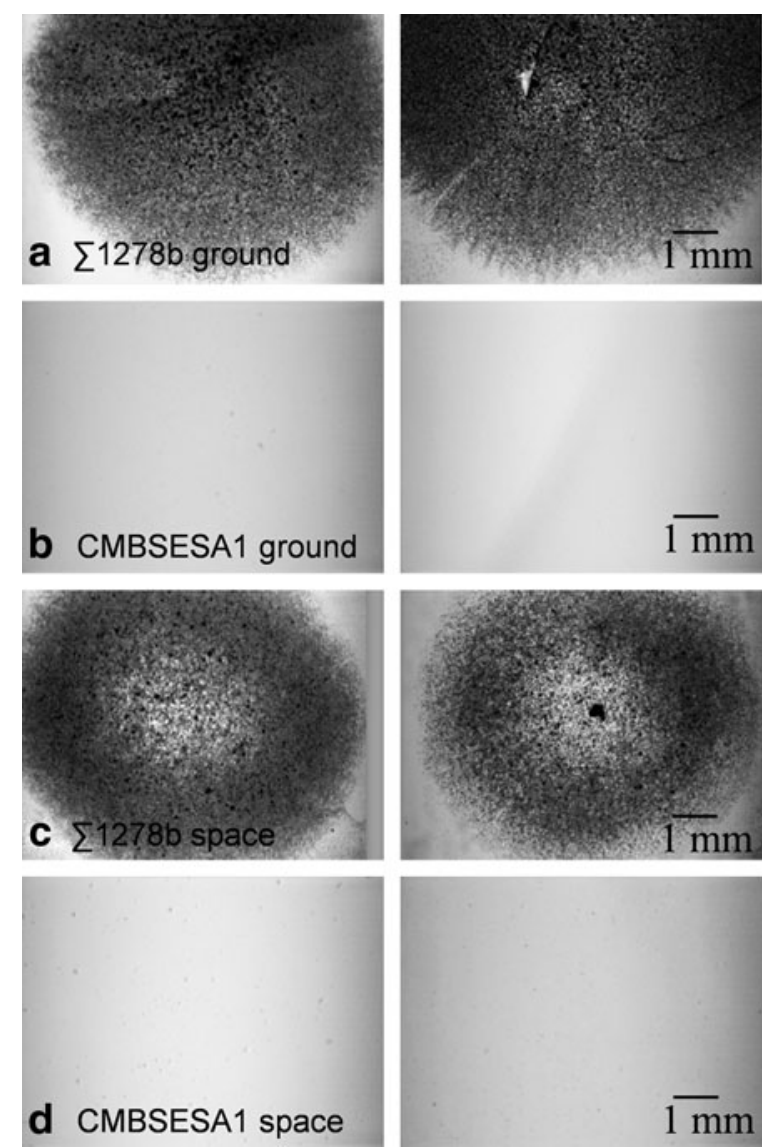

FIG. 3. Invasive growth assessment. Photographs of the agar surface after removal of the yeast colony with a cell scraper. (a) $\Sigma 1278$ b cells on $2 \%$ YPD agar, ground sample. (b) Industrial brewer's yeast cells on 2\% YPD agar, ground sample. (c) Invasive $\Sigma 1278 \mathrm{~b}$ cells on $2 \%$ YPD agar, spaceflight sample. (d) Industrial brewer's yeast cells on 2\% YPD agar, spaceflight sample. For every condition, two replicates are shown.

laboratory strain. A minor part showed a unipolar and random budding pattern. In microgravity, the percentage of random budding pattern was increased by $5.2 \%( \pm 2.6 \%)$. The majority of the industrial brewer's strain cells showed a random budding pattern. In microgravity, the percentage of random budding pattern was increased by $6.0 \%( \pm 3.3 \%)$.

\subsection{Proteomics}

Soluble proteins were extracted from yeast colonies grown in normal gravity and microgravity, and subsequently separated with the 2D-PAGE technique as described above. Figure 5 shows an example of the 2D-PAGE maps of $S$. cerevisiae $\Sigma 1278$ b soluble proteins. In total, 1407 spots were matched over all the different gels. For quantitative analysis, 557 spots were selected, which were present in two out of the three gels of both control and microgravity proteome maps. With use of a filter with a maximum coefficient of variation of $60 \%$ and a regulation factor of 2, 32 spots were found to be upregulated in microgravity, and 37 spots were downregulated. An additional filter was set up, of which the focus was to filter out the spots present in either group and have a 

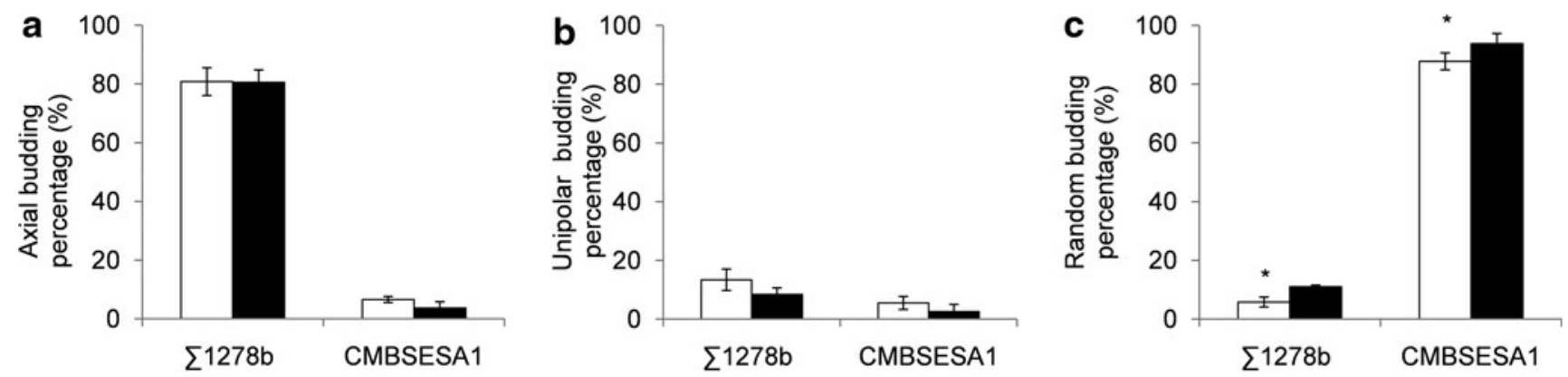

FIG. 4. Bud scar pattern analysis of $\Sigma 1278 \mathrm{~b}$ and CMBSESA1 grown on $2 \%$ YPD agar under normal gravity (white bars) and microgravity (black bars). Axial (a), unipolar (b) and random (c) bud scar distribution are expressed in percentages (\%). For each sample, at least 150 cells with three or more bud scars were analyzed. Asterisks indicate statistically significant differences between ground and spaceflight samples $\left({ }^{*} p<0.05\right)$; error bars correspond to the standard deviation.

coefficient of variation of $60 \%$ or less. In the microgravity group, 45 such spots were found, and 38 spots were found in the control group. The mass spectrometric identification rate of proteins with an altered spot intensity was 65\%; for the proteins present in either group the rate was 31\%. This lower percentage of proteins present in one group could be explained by the fact that these protein spots in general have a lower intensity. An overview of all the identified proteins can be found in Table 1. Details on the protein identifications are provided in Supplementary Table S1 (Supplementary Data are available online at www.liebertonline.com/ast).

It can be noted that on the proteome map of the microgravity-grown yeast samples (A), less proteins are visible in the high-mass range in comparison to the proteome map of normal gravity-grown colonies (Fig. 5). This could indicate increased protein degradation in microgravity. This was confirmed by the mass spectrometric analysis, which revealed a partial protein coverage by peptide map fingerprinting and by the fact that some protein spots are displayed in a $\mathrm{pI} / \mathrm{Mr}$ range, which deviates from the theoretical values based on the protein sequence. These proteins are marked in Table 1 with an asterisk. Markedly, we found a spot that corresponds to ubiquitin in the microgravity samples that was absent in the control samples and indicates enhanced degradosome activity rather than a random protein degradation process.

The last column in Table 1 indicates the biological process in which the identified proteins are involved. It is clear that we mainly detected changes in abundance for proteins involved in energy metabolism and in stress response (oxidative stress proteins and chaperones). Indeed, of the 47 identified proteins, 25 were involved in energy metabolism and 11 in stress and protein folding.

\section{Discussion}

Under specific environmental conditions, the baker's yeast Saccharomyces cerevisiae can undergo a transition from its characteristic single cell growth form to short filaments that consist of elongated cells. In haploid cells, this process is called invasive growth and occurs on rich semi-solid media after glucose depletion (Cullen and Sprague, 2000; Prusty et al., 2004). Invasive growth is considered as a means for otherwise non-motile cells to forage for nutrients or to colonize hosts, for instance, plants or humans (Hube, 2004; Prusty et al., 2004; Kumamoto and Vinces, 2005). Such
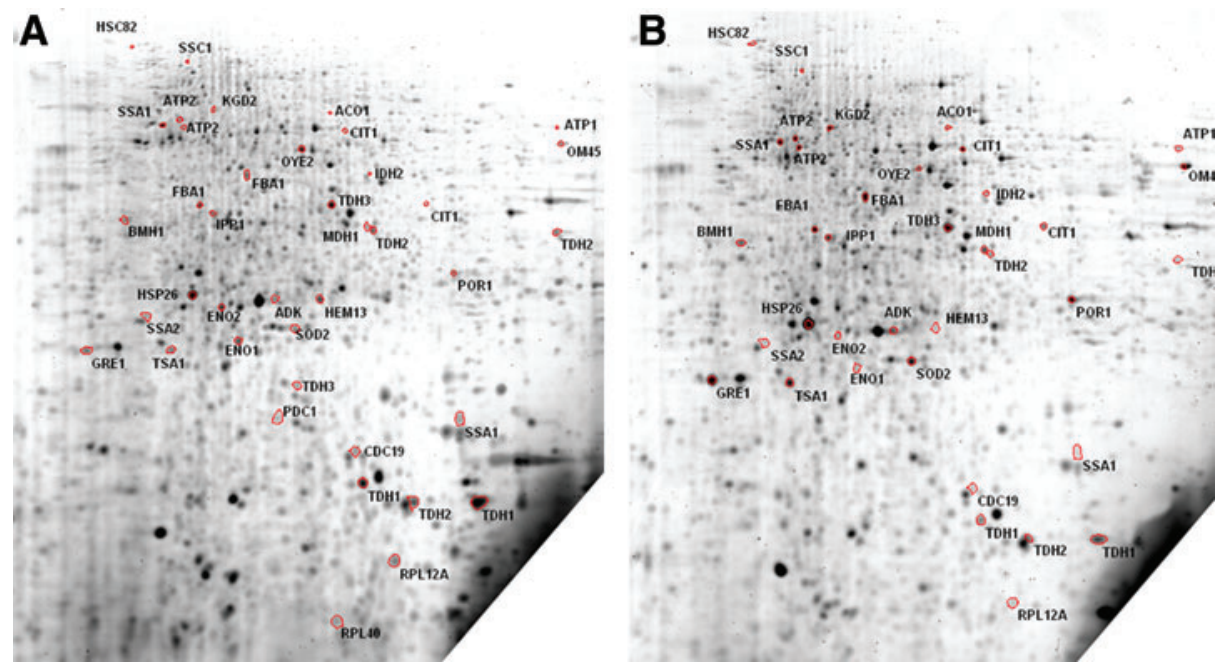

FIG. 5. 2D-PAGE images of the complete proteome of the $\Sigma 1278 b$ strain grown in (A) microgravity and (B) normal gravity. Identified differentially expressed proteins are labeled on both microgravity (A) and normal gravity (B) proteome map. Color images available online at www.liebertonline .com/ast. 
Table 1. Overview of All 1278b Proteins Identified as Being Differentially Regulated in Microgravity in Comparison to Normal Gravity

\begin{tabular}{|c|c|c|c|c|}
\hline $\begin{array}{l}\text { Gene } \\
\text { name }\end{array}$ & Description & $\begin{array}{l}\text { Regulation } \\
\text { factor }\end{array}$ & $\begin{array}{c}\text { Mascot } \\
\text { score }\end{array}$ & Function/pathway \\
\hline PDC1 & Major of three pyruvate decarboxylase isozymes & 2.10 & 83 & glucose fermentation \\
\hline ENO & Enolase & 2.95 & 47 & glycolysis \\
\hline TDH2 & Glyceraldehyde-3-phosphate dehydrogenase, isozyme 2 & 2.90 & 67 & glycolysis \\
\hline TDH1* & Glyceraldehyde-3-phosphate dehydrogenase, isozyme 1 & 2.48 & 41 & glycolysis \\
\hline TDH1* & Glyceraldehyde-3-phosphate dehydrogenase, isozyme 1 & 2.24 & 41 & glycolysis \\
\hline ENO & Enolase & 2.14 & 97 & glycolysis \\
\hline TDH2 & Glyceraldehyde-3-phosphate dehydrogenase, isozyme 2 & 2.11 & 82 & glycolysis \\
\hline TDH2 & Glyceraldehyde-3-phosphate dehydrogenase, isozyme 2 & 2.09 & 93 & glycolysis \\
\hline CDC19 & Pyruvate kinase & 2.07 & 91 & glycolysis \\
\hline TDH2 & Glyceraldehyde-3-phosphate dehydrogenase, isozyme 2 & 2.00 & 42 & glycolysis \\
\hline HEM13 & Coproporphyrinogen III oxidase & 2.33 & 46 & haem biosynthesis \\
\hline OYE2 & Conserved NADPH oxidoreductase & 2.21 & 246 & sterol metabolism \\
\hline$S S A 2^{*}$ & ATP binding protein involved in protein folding & 2.19 & 123 & stress/protein folding \\
\hline$S S A 1^{*}$ & ATPase involved in protein folding and nuclear localization & 2.08 & 95 & stress/protein folding \\
\hline RPL12A & Protein component of the large (60S) ribosomal subunit & 2.73 & 48 & translation \\
\hline $\mathrm{TDH}^{*}$ & Glyceraldehyde-3-phosphate dehydrogenase, isozyme 3 & present & N.A. & glycolysis \\
\hline RPL40 & Ubiquitin & present & 103 & protein degradation \\
\hline POR1 & Outer mitochondrial membrane porin & 0.37 & 57 & apoptosis \\
\hline KGD2 & Dihydrolipoyllysine succinyltransferase & 0.21 & 63 & citric acid cycle \\
\hline CIT1 & Citrate synthase & 0.29 & 115 & citric acid cycle \\
\hline MDH1 & Malate dehydrogenase & 0.33 & 95 & citric acid cycle \\
\hline IDH2 & Isocitrate dehydrogenase & 0.37 & 164 & citric acid cycle \\
\hline CIT1 & Citrate synthase & 0.43 & 70 & citric acid cycle \\
\hline ACO1 & Citrate hydrolase & 0.49 & 64 & citric acid cycle \\
\hline IDH2 & Isocitrate dehydrogenase & 0.49 & 125 & citric acid cycle \\
\hline ATP2 & ATP synthase subunit $b$ & 0.31 & 104 & energy \\
\hline ATP1 & ATP synthase subunit a & 0.35 & 58 & energy \\
\hline ATP2 & ATP synthase subunit $b$ & 0.40 & 59 & energy \\
\hline BMH1 & $14-3-3$ protein, major isoform & 0.36 & 119 & exocytosis \\
\hline TDH3 & Glyceraldehyde-3-phosphate dehydrogenase, isozyme 3 & 0.41 & 87 & glycolysis \\
\hline FBA1 & Fructose bisphosphate aldolase & 0.44 & 145 & gluconeogenesis \\
\hline FBA1 & Fructose bisphosphate aldolase & 0.45 & 91 & gluconeogenesis \\
\hline IPP1 & Inorganic pyrophosphatase & 0.44 & 90 & oxidative phosphorylation \\
\hline SOD2 & Superoxide dismutase Mn & 0.40 & 61 & oxidative stress \\
\hline TSA1 & Peroxiredoxin & 0.40 & 53 & oxidative stress \\
\hline HSP26 & Heat shock protein 26 & 0.34 & 105 & protein folding/stress \\
\hline HSC82 & ATP-dependent molecular chaperone HSC82 & 0.36 & 109 & protein folding/stress \\
\hline SSC1 & Heat shock protein SSC1 & 0.41 & 70 & protein folding/stress \\
\hline SSA1 & Heat shock protein SSA1 & 0.46 & 105 & protein folding/stress \\
\hline SSA1 & Heat shock protein SSA1 & 0.48 & 83 & protein folding/stress \\
\hline$A D K$ & Adenylate kinase & 0.36 & 99 & purine metabolism \\
\hline GRE1 & Hydrophilin & 0.19 & 120 & stress induced \\
\hline OM45 & Mitochondrial outer membrane OM 45 & 0.36 & 94 & unknown \\
\hline ACH1 & Acetyl coA hydrolase & absent & 85 & acetate metabolism \\
\hline$A L D 4$ & Aldehyde dehydrogenase & absent & 92 & ethanol metabolism \\
\hline HSP60 & Heat shock protein 60 & absent & 83 & protein folding \\
\hline $\mathrm{Rps} 0 \mathrm{~B}$ & Protein component of the small (40S) ribosomal subunit & absent & 88 & translation \\
\hline
\end{tabular}

All proteins were identified with at least two peptides in MS/MS fragmentation. When protein score is defined as N.A. no significant protein identification could be obtained, but protein identification criteria (see Materials and Methods) were met. Regulation factor is the fold change of protein under microgravity: when a protein was solely present in microgravity, it is depicted as present; when only present in normal gravity, it is depicted as absent.

transitions may represent a considerable risk during spaceflight; therefore, the impact of microgravity conditions was assessed.

In this study, a highly invasive S. cerevisiae $\Sigma 1278$ b strain and a non-invasive industrial brewer's CMBSESA1 strain were grown as colonies on a semi-solid medium in normal gravity and microgravity in the ISS. First, a remarkable de- crease in two-dimensional spreading for $\Sigma 1278$ b was observed under microgravity conditions, which was not observed for the industrial brewer's yeast. On the other hand, Johanson et al. (2007) remarked more pronounced growth of yeast cells stored in distilled water in microgravity compared to normal gravity. Liu et al. (2008) found faster growth rate, shorter lag phase periods, and higher final 
biomass in normal gravity, using yeast samples returned from spaceflight.

The discrepancy in this study suggests a strain-dependent microgravity response. A first hypothesis for the twodimensional spreading differences between the two strains observed in this work is that the colony growth morphology is affected, resulting, for example, in a more-pronounced growth in the $z$ direction under microgravity conditions, which was not measurable by photographing the plates. Analogously, under LSMMG conditions, it has also been demonstrated that Escherichia coli biofilms are thicker than those observed under normal gravity conditions (Lynch et al., 2006). A second hypothesis could be that cellular metabolism and cell growth were affected, for instance, because of stress or another disadvantageous or harmful microgravity response, with a smaller colony size as a result.

Two mechanisms for the first hypothesis are proposed. First, the absence of gravity could make it physically easier for the colony to grow in the $z$ direction. Secondly, the Flo11 adhesin sketches characteristic complex colony morphology and mat patterns as well as colony size in $S$. cerevisiae (Reynolds and Fink, 2001; Reynolds et al., 2008; Granek and Magwene, 2010). It could be that the expression of the only FLO gene expressed in $\Sigma 1278 b$, FLO11, is altered under microgravity conditions, which resulted in a smaller colony size. Accordingly, the polyploid CMBSESA1 spreading may stay unaffected because higher ploidy correlates with lower FLO11 expression (Galitski et al., 1999; Reynolds and Fink, 2001; Granek and Magwene, 2010). Under microgravity, invasive growth, which is Flo11p-dependent, was reduced in the center of the $\Sigma 1278$ b colonies. Possibly, reduced FLO11 expression at the center of the colony decreased the likeliness of the cells to grow into the agar, which resulted in an enhanced colony growth in the $z$ direction. On the other hand, a previous study showed that FLO11 expression was shown to be uniform at different positions in a yeast mat, a differentiated layer of cells on very low-density $0.3 \%$ agar (Reynolds et al., 2008).

There are also some indications for the second hypothesis. $\Sigma 1278$ b is characterized by a hyperactive cAMP/PKA pathway, which causes the strong agar-invasive growth but also the defectiveness of stress-responsive gene induction (Stanhill et al., 1999). Possibly, microgravity is a stress condition for yeast cells, and because of the absence of an appropriate stress response, this led to reduced growth in the $\Sigma 1278 \mathrm{~b}$ strain. Indeed, global proteome changes were observed for the $\Sigma 1278 \mathrm{~b}$ strain with a remarkable upregulation of proteins linked to anaerobiosis, which may be responsible for slower growth ( $c f$. infra). Alternatively, the stress could be caused by the high total absorbed dose of ionizing radiation recorded during the flight experiment, which was about 70 times higher than that on Earth for the same period (Goossens et al., 2006; Vanhavere et al., 2008). CMBSESA1 is an industrial brewer's strain adapted to stress conditions and has a polyploid genome, which is correlated to an increased fitness and may result in an increased stress resistance (Sliwa et al., 2004).

There is a clear upregulation of key glycolytic enzymes glyceraldehyde-3-phosphate dehydrogenase, pyruvate kinase, and a subunit from pyruvate decarboxylase, while the tricarboxylic acid cycle and some oxidative phosphorylation enzymes are less abundant in microgravity conditions. We also observed a reduced production of gluconeogenic enzymes such as fructose 1,6 biphosphate aldolase, and of acetyl-CoA hydrolase in microgravity, which is proven to be involved in oxidative metabolism during propagation (Kobi et al., 2004). The shift to anaerobiosis is further supported by the observation that oxidative stress proteins such as superoxide dismutase and peroxiredoxin were downregulated. Our data provide a significant correspondence with previous proteomic analysis of anaerobic versus aerobically grown S. cerevisiae (Bruckmann et al., 2009). This also includes a reduced abundance of several heat shock proteins involved in protein folding or protein translocation into mitochondria, the mitochondrial outer membrane protein OM45. Remarkably, no gas exchange could occur as the culture plates were sealed hermetically in the hardware used for the normal gravity and microgravity samples.

Microgravity influenced the budding pattern of the yeast cells grown on a solid agar medium. An increase of randomly distributed bud scars in microgravity of $5.2 \%$ was found for the haploid $\Sigma 1278$ b cells and of $6.0 \%$ for the polyploid cells of the industrial brewer's strain. This increase is smaller than the $\pm 12 \%$ increase (Walther et al., 1996) or $\pm 11.7 \%$ (Purevdorj-Gage et al., 2006) observed previously with diploid cells grown in liquid culture under, respectively, microgravity and LSMMG conditions. This difference may be due to growth on semi-solid instead of liquid media or due to the different ploidy of the strains used in our study, which would lead to less susceptibility for disturbance in the budding pattern. Walther et al. (1996) hypothesized that this disturbance may possibly be the result of the influence of microgravity on the cytoskeleton, which would influence the position of the bud scars. Purevdorj-Gage et al. (2006), however, postulated that the altered random budding pattern in LSMMG conditions was probably not due to a change in the cytoskeleton organization but rather due to a changed expression of genes with an upstream role in budding processes, such as bud site selection and polarity establishment.

Only a few studies have focused on yeast growth under microgravity conditions (cf. supra). However, spaceflight has been shown to affect various bacterial growth parameters (Klaus, 2002; Nickerson et al., 2004; Horneck et al., 2010), including increased final cell numbers compared to normal gravity controls for non-motile microbes grown in liquid suspension cultures (Kacena et al., 1999; Benoit and Klaus, 2007; Rosenzweig et al., 2010), and shortened lag phases (Kacena and Todd, 1997; Klaus, 1998; Kacena et al., 1999). It is proposed that weightlessness allows the cells to remain evenly distributed in the liquid medium, which consequently alters the chemical makeup of their surrounding fluid and, indirectly, their physiological behavior (Benoit and Klaus, 2005). Microbial growth on semi-solid agar medium is not characterized by these specific liquid fluid mechanics effects and thus reduces the unknowns associated with spaceflight microorganism cultures in suspension (Kacena and Todd, 1997; Kacena et al., 1999; Benoit and Klaus, 2007). Oxygen and carbon dioxide transport modeling around $S$. cerevisiae colonies further revealed that the concentration gradients surrounding the colonies in normal and microgravity conditions are practically the same (results not shown). It thus appears that the two-dimensional spreading differences on semi-solid agar and the observed changes in physiology in 
this study can be indicated as a direct microgravity effect that may be sensed by yeast cells as a stress condition. Expression changes were previously observed in the stress response element genes SSA4, YIL052C, and YST2 with transcription regulation involving Sfp1p and Msn4p (Coleman et al., 2008). Altered stress resistance in liquid cultivation of E. coli and Salmonella typhimurium has also been described for simulated space conditions (Nickerson et al., 2000; Gao et al., 2001; Wilson et al., 2002, 2007).

In our future microgravity experiments, we will search for interesting insights for the elucidation of gravity-sensor mechanisms in yeast cells. The effect of microgravity conditions on S. cerevisiae liquid and on semi-solid agar cultivation will be investigated more deeply with a systems biology approach (transcriptomics, proteomics, and fluxomics). Therefore, yeast strains (BY4742 for liquid cultivation and $\Sigma 1278$ b for semi-solid agar cultivation) overexpressing one specific FLO gene will be grown in microgravity, as well as the BY4742 strain containing a functional Flo8p.

\section{Acknowledgments}

This work was supported by the Belgian Federal Science Policy Office, Danish Agency for Space and Technology, and the European Space Agency PRODEX program. Geert Toye is acknowledged for his help with setting up the microgravity experiment at Baikonur (Kazakhstan). Natalie Leys, Max Mergeay, and Annik Dams from SCK (Mol, Belgium) are acknowledged for their help during the experiment preflight preparation in Baikonur (Kazakhstan). The authors are grateful to all people involved in the preparation and performance of the microgravity experiment (ESA/ESTEC, EADS, DLR MUSC, BIOTESC).

\section{Author Disclosure Statement}

No competing financial interests exist.

\section{Abbreviations}

2D-PAGE, two-dimensional polyacrylamide gel electrophoresis; ACN, acetonitrile; IPG, immobilized $\mathrm{pH}$ gradient; ISS, International Space Station; LSMMG, low-shear modeled microgravity; MS/MS, tandem mass spectrometry; SDS, sodium dodecyl sulfate; SDS-PAGE, sodium dodecyl sulfate polyacrylamide gel electrophoresis.

\section{References}

Abramoff, M.D., Magelhaes, P.J., and Ram, S.J. (2004) Image processing with ImageJ. Biophotonics International 11:36-42.

Altenburg, S.D., Nielsen-Preiss, S.M., and Hyman, L.E. (2008) Increased filamentous growth of Candida albicans in simulated microgravity. Genomics Proteomics Bioinformatics 6:42-50.

Bayly, J.C., Douglas, L.M., Pretorius, I.S., Bauer, F.F., and Dranginis, A.M. (2005) Characteristics of Flo11-dependent flocculation in Saccharomyces cerevisiae. FEMS Yeast Res 5:11511156.

Benoit, M.R. and Klaus, D.M. (2005) Can genetically modified Escherichia coli with neutral buoyancy induced by gas vesicles be used as an alternative method to clinorotation for microgravity studies? Microbiology 151:69-74.

Benoit, M.R. and Klaus, D.M. (2007) Microgravity, bacteria, and the influence of motility. Adv Space Res 39:1225-1232.
Blankenship, J.R. and Mitchell, A.P. (2006) How to build a biofilm: a fungal perspective. Curr Opin Microbiol 9:588-594.

Bony, M., Thines-Sempoux, D., Barre, P., and Blondin, B. (1997) Localization and cell surface anchoring of the Saccharomyces cerevisiae flocculation protein Flo1p. J Bacteriol 179: 4929-4936.

Borchers, A.T., Keen, C.L., and Gershwin, M.E. (2002) Microgravity and immune responsiveness: implications for space travel. Nutrition 18:889-898.

Braus, G.H., Grundmann, O., Brückner, S., and Mösch, H.-U. (2003) Amino acid starvation and Gcn4p regulate adhesive growth and FLO11 gene expression in Saccharomyces cerevisiae. Mol Biol Cell 14:4272-4284.

Bruckmann, A., Hensbergen, P.J., Balog, C.I.A., Deelder, A.M., Brandt, R., Snoek, I.S.I., Steensma, H.Y., and van Heusden, G.P.H. (2009) Proteome analysis of aerobically and anaerobically grown Saccharomyces cerevisiae cells. J Proteomics 71:662669.

Coleman, C.B., Allen, P.L., Rupert, M., Goulart, C., Hoehn, A., Stodieck, L.S., and Hammond, T.G. (2008) Novel Sfp1 transcriptional regulation of Saccharomyces cerevisiae gene expression changes during spaceflight. Astrobiology 8:1071-1078.

Cullen, P.J. and Sprague, G.F. (2000) Glucose depletion causes haploid invasive growth in yeast. Proc Natl Acad Sci USA 97:13619-13624.

Douglas, L.M., Li, L., Yang, Y., and Dranginis, A.M. (2007) Expression and characterization of the flocculin Flo11/Muc1, a Saccharomyces cerevisiae mannoprotein with homotypic properties of adhesion. Eukaryot Cell 6:2214-2221.

Dranginis, A.M., Rauceo, J.M., Coronado, J.E., and Lipke, P.N. (2007) A biochemical guide to yeast adhesins: glycoproteins for social and antisocial occasions. Microbiol Mol Biol Rev 71:282-294.

Evans, S.E. (2010) Coping with Candida infections. Proc Am Thorac Soc 7:197-203.

Fichtner, L., Schulze, F., and Braus, G.H. (2007) Differential Flo8p-dependent regulation of FLO1 and FLO11 for cell-cell and cell-substrate adherence of S. cerevisiae. Mol Microbiol 66:1276-1289.

Galitski, T., Saldanha, A.J., Styles, C.A., Lander, E.S., and Fink, G.R. (1999) Ploidy regulation of gene expression. Science 285:251-254.

Gao, Q., Fang, A., Pierson, D.L., Mishra, S.K., and Demain, A.L. (2001) Shear stress enhances microcin B17 production in a rotating wall bioreactor, but ethanol stress does not. Appl Microbiol Biotechnol 56:384-387.

Goldstein, A.L. and McCusker, J.H. (2001) Development of Saccharomyces cerevisiae as a model pathogen: a system for the genetic identification of gene products required for survival in the mammalian host environment. Genetics 159:499-513.

Goossens, O., Vanhavere, F., Leys, N., De Boever, P., O'Sullivan, D., Zhou, D., Spurny, F., Yukihara, E.G., Gaza, R., and McKeever, S.W.S. (2006) Radiation dosimetry for microbial experiments in the International Space Station using different etched track and luminescent detectors. Radiat Prot Dosimetry 120:433-437.

Graf, C. and Gavazzi, G. (2007) Saccharomyces cerevisiae fungemia in an immunocompromised patient not treated with Saccharomyces boulardii preparation. J Infect 54:310-311.

Granek, J.A. and Magwene, P.M. (2010) Environmental and genetic determinants of colony morphology in yeast. PLoS Genet 6:e1000823.

Gullo, A. (2009) Invasive fungal infections: the challenge continues. Drugs 69:65-73. 
Guo, B., Styles, C.A., Feng, Q., and Fink, G.R. (2000) A Saccharomyces cerevisiae gene family involved in invasive growth, cell-cell adhesion, and mating. Proc Natl Acad Sci USA 97:12158-12163.

Horneck, G., Klaus, D.M., and Mancinelli, R.L. (2010) Space microbiology. Microbiol Mol Biol Rev 74:121-156.

Hube, B. (2004) From commensal to pathogen: stage- and tissuespecific gene expression of Candida albicans. Curr Opin Microbiol 7:336-341.

Johanson, K., Allen, P.L., Gonzalez-Villalobos, R.A., Nesbit, J., Nickerson, C.A., Höner zu Bentrup, K., Wilson, J.W., Ramamurthy, R., D'Elia, R., Muse, K.E., Hammond, J., Freeman, J., Stodieck, L.S., and Hammond, T.G. (2007) Haploid deletion strains of Saccharomyces cerevisiae that determine survival during space flight. Acta Astronaut 60:460-471.

Kacena, M. and Todd, P. (1997) Growth characteristics of E. coli and $B$. subtilis cultured on an agar substrate in microgravity. Microgravity Sci Technol 10:58-62.

Kacena, M.A., Manfredi, B., and Todd, P. (1999) Effects of space flight and mixing on bacterial growth in low volume cultures. Microgravity Sci Technol 12:74-77.

Klaus, D.M. (1998) Microgravity and its implications for fermentation biotechnology. Trends Biotechnol 16:369-373.

Klaus, D.M. (2002) Space microbiology: microgravity and microorganisms. In Encyclopedia of Environmental Microbiology, edited by G. Britton, John Wiley \& Sons, New York, pp 2299623004.

Klis, F.M., Sosinska, G.J., de Groot, P.W.J., and Brul, S. (2009) Covalently linked cell wall proteins of Candida albicans and their role in fitness and virulence. FEMS Yeast Res 9:10131028.

Kobayashi, O., Hayashi, N., Kuroki, R., and Sone, H. (1998) Region of Flo1 proteins responsible for sugar recognition. J Bacteriol 180:6503-6510.

Kobi, D., Zugmeyer, S., Potier, S., and Jaquet-Gutfreund, L. (2004) Two-dimensional protein map of an "ale"-brewing yeast strain: proteome dynamics during fermentation. FEMS Yeast Res 5:210-230.

Kojic, E.M. and Darouiche, R.O. (2004) Candida infections of medical devices. Clin Microbiol Rev 17:255-267.

Kron, S.J., Styles, C.A., and Fink, G.R. (1994) Symmetric cell division in pseudohyphae of the yeast Saccharomyces cerevisiae. Mol Biol Cell 5:1003-1022.

Kumamoto, C.A. and Vinces, M.D. (2005) Contributions of hyphae and hypha-co-regulated genes to Candida albicans virulence. Cell Microbiol 7:1546-1554.

Lambrechts, M.G., Bauer, F.F., Marmur, J., and Pretorius, I.S. (1996) Muc1, a mucin-like protein that is regulated by Mss10, is critical for pseudophyphal differentiation in yeast. Proc Natl Acad Sci USA 93:8419-8424.

Leys, N., Baatout, S., Rosier, C., Dams, A., s'Heeren, C., Wattiez, R., and Mergeay, M. (2009) The response of Cupriavidus metallidurans $\mathrm{CH} 34$ to spaceflight in the international space station. Antonie van Leeuwenhoek 96:227-245.

Liu, H.-Z., Wang, Q., Liu, X.-Y., and Tan, S.-S. (2008) Effects of spaceflight on polysaccharides of Saccharomyces cerevisiae cell wall. Appl Microbiol Biotechnol 81:543-550.

Lo, W.-S. and Dranginis, A.M. (1996) FLO11, a yeast gene related to the STA genes, encodes a novel cell surface flocculin. J Bacteriol 178:7144-7151.

Lord, M., Chen, T., Fujita, A., and Chant, J. (2002) Analysis of budding patterns. Methods Enzymol 350:131-141.

Lynch, S.V., Mukundakrishnan, K., Benoit, M.R., Ayyaswamy, P.S., and Matin, A. (2006) Escherichia coli biofilms formed under low-shear modeled microgravity in a ground-based system. Appl Environ Microbiol 72:7701-7710.

McCusker, J.H., Clemons, K.V., Stevens, D.A., and Davis, R.W. (1994a) Saccharomyces cerevisiae virulence phenotype as determined with CD-1 mice is associated with the ability to grow at $42^{\circ} \mathrm{C}$ and for pseudohyphae. Infect Immun 62:5447-5455.

McCusker, J.H., Clemons, K.V., Stevens, D.A., and Davis, R.W. (1994b) Genetic characterization of pathogenic Saccharomyces cerevisiae isolates. Genetics 136:1261-1269.

Nickerson, C.A., Ott, C.M., Mister, S.J., Morrow, B.J., BurnsKeliher, L., and Pierson, D.L. (2000) Microgravity as a novel environmental signal affecting Salmonella enterica serovar typhimurium virulence. Infect Immun 68:3147-3152.

Nickerson, C.A., Ott, C.M., Wilson, J.W., Ramamurthy, R., and Pierson, D.L. (2004) Microbial responses to microgravity and other low-shear environments. Microbiol Mol Biol Rev 68:345361.

Palková, Z. and Vachová, L. (2006) Life within a community: benefit to yeast long-term survival. FEMS Microbiol Rev 30:806-824.

Pirt, S.J. (1967) A kinetic study of the mode of growth of surface colonies of bacteria and fungi. J Gen Microbiol 47:181-197.

Pringle, J.R. (1991) Staining of bud scars and other cell wall chitin with calcofluor. Methods Enzymol 194:732-735.

Prusty, R., Grisafi, P., and Fink, G.R. (2004) The plant hormone indoleacetic acid induces invasive growth in Saccharomyces cerevisiae. Proc Natl Acad Sci USA 101:4153-4157.

Purevdorj-Gage, B., Sheehan, K.B., and Hyman, L.E. (2006) Effects of low-shear modeled microgravity on cell function, gene expression and phenotype in Saccharomyces cerevisiae. Appl Environ Microbiol 72:4569-4575.

Ramage, G., Martínez, J.P., and López-Ribot, J.L. (2006) Candida biofilms on implanted biomaterials: a clinically significant problem. FEMS Yeast Res 6:979-986.

Reynolds, T.B. and Fink, G.R. (2001) Bakers' yeast, a model for fungal biofilm formation. Science 291:878-881.

Reynolds, T.B., Jansen, A., Peng, X., and Fink, G.R. (2008) Mat formation in Saccharomyces cerevisiae requires nutrient and $\mathrm{pH}$ gradients. Eukaryot Cell 7:122-130.

Roberts, R.L. and Fink, G.R. (1994) Elements of a single MAP kinase cascade in Saccharomyces cerevisiae mediate two developmental programs in the same cell type: mating and invasive growth. Genes Dev 8:2974-2985.

Rosenzweig, J.A., Abogunde, O., Thomas, K., Lawal, A., Nguyen, Y.-U., Sodipe, A., and Jejelowo, O. (2010) Spaceflight and modeled microgravity effects on microbial growth and virulence. Appl Microbiol Biotechnol 85:885-891.

Sheehan, K.B., McInnerney, K., Purevdorj-Gage, B., Altenburg, S.D., and Hyman, L.E. (2007) Yeast genomic expression patterns in response to low-shear modeled microgravity. BMC Genomics 8:3.

Sliwa, P., Kluz, J., and Korona, R. (2004) Mutational load and the transition between diploidy and haploidy in experimental populations of the yeast Saccharomyces cerevisiae. Genetica 121:285-293.

Smukalla, S., Caldara, M., Pochet, N., Beauvais, A., Guadagnini, S., Yan, C., Vinces, M.D., Jansen, A., Prevost, M.-C., Latgé, J.P., Fink, G.R., Foster, K.R., and Verstrepen, K.J. (2008) FLO1 is a hyper-variable green beard gene that drives a transition to multicellularity in budding yeast. Cell 135:726-737.

Sonnenfeld, G. (1999) Space flight, microgravity, stress, and immune responses. Adv Space Res 23:1945-1953.

Sonnenfeld, G. (2002) The immune system in space and microgravity. Med Sci Sports Exerc 34:2021-2027. 
Stanhill, A., Schick, N., and Engelberg, D. (1999) The yeast ras/ cyclic AMP pathway induces invasive growth by suppressing the cellular stress response. Mol Cell Biol 19:7529-7538.

Taylor, G.R., Konstantinova, I., Sonnenfeld, G., Jennings, R., and Sjoerd, L.B. (1997) Changes in the immune system during and after spaceflight. Adv Space Res 6:1-32.

Teunissen, A.W.R.H., and Steensma, H.Y. (1995) Review: the dominant flocculation genes of Saccharomyces cerevisiae constitute a new subtelomeric gene family. Yeast 11:1001-1013.

Van Mulders, S.E., Christianen, E., Saerens, S.M.G., Daenen, L., Verbelen, P.J., Willaert, R., Verstrepen, K.J., and Delvaux, F.R. (2009) Phenotypic diversity of Flo protein family-mediated adhesion in Saccharomyces cerevisiae. FEMS Yeast Res 9:178-190.

Vanhavere, F., Genicot, J.L., O'Sullivan, D., Zhou, D., Spurný, F., Jadrnícková, I., Sawakuchi, G.O., and Yukihara, E.G. (2008) DOsimetry of BIological EXperiments in SPace (DOBIES) with luminescence (OSL and TL) and track etch detectors. Radiat Meas 43:694-697.

Verstrepen, K.J. and Klis, F.M. (2006) Flocculation, adhesion and biofilm formation in yeasts. Mol Microbiol 60:5-15.

Walther, I., Bechler, B., Müller, O., Hunzinger, E., and Cogoli, A. (1996) Cultivation of Saccharomyces cerevisiae in a bioreactor in microgravity. J Biotechnol 47:113-127.

West, J.B. (2000) Physiology of a microgravity environment historical perspectives: physiology in microgravity. J Appl Physiol 89:379-384.

Wilson, J.W., Ott, C.M., Ramamurthy, R., Porwollik, S., McClelland, M., Pierson, D.L., and Nickerson, C.A. (2002)
Low-shear modeled microgravity alters the Salmonella enterica serovar Typhimurium stress response in an RpoS-independent manner. Appl Microbiol Biotechnol 68:5408-5416.

Wilson, J.W., Ott, C.M., zu Bentrup, K.H.n., Ramamurthy, R., Quick, L., Porwollik, S., Cheng, P., McClelland, M., Tsaprailis, G., Radabaugh, T., Hunt, A., Fernandez, D., Richter, E., Shah, M., Kilcoyne, M., Joshi, L., Nelman-Gonzalez, M., Hing, S., Parra, M., Dumars, P., Norwood, K., Bober, R., Devich, J., Ruggles, A., Goulart, C., Rupert, M., Stodieck, L., Stafford, P., Catella, L., Schurr, M.J., Buchanan, K., Morici, L., McCracken, J., Allen, P., Baker-Coleman, C., Hammond, T., Vogel, J., Nelson, R., Pierson, D.L., Stefanyshyn-Piper, H.M., and Nickerson, C.A. (2007) Space flight alters bacterial gene expression and virulence and reveals a role for global regulator Hfq. Proc Natl Acad Sci USA 104:16299-16304.

Address correspondence to: Ronnie Willaert Laboratory of Structural Biology (SBB) Vrije Universiteit Brussel Pleinlaan 2, B-1050 Brussel

Belgium

E-mail: Ronnie.Willaert@vub.ac.be

Submitted 12 July 2010 Accepted 25 October 2010 
